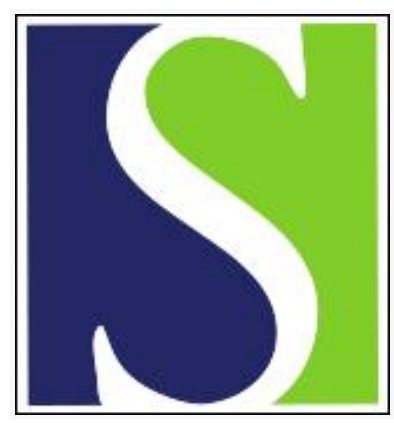

Scand J Work Environ Health 2020;46(2):143-151

https://doi.org/10.5271/sjweh.3829

Published online: 02 May 2019, Issue date: 01 Mar 2020

Shift work and its relation with meal and snack patterns among healthcare workers

by Hulsegge G, Loef B, Benda T, van der Beek AJ, Proper KI

$\overline{\text { Shift workers had a similar meal and snack frequency and ate snacks }}$ of similar quality as day workers. However, snacking patterns differed across day, evening, and night shifts. As these meal and snack patterns are not necessarily good for health, future research should investigate which meal and snack patterns are best for health to improve dietary recommendations for shift workers.

Affiliation: Centre for Nutrition, Prevention and Health Services, National Institute for Public Health and the Environment, P.O. Box 1, 3720 BA, Bilthoven, The Netherlands. karin.proper@rivm.nl

The following article refers to this text: 2020;46(5):516-524

Key terms: diet; dietary intake; healthcare worker; meal pattern; night work; nutrition; shift work; shift worker; snack; snack pattern; snacking behavior

This article in PubMed: www.ncbi.nlm.nih.gov/pubmed/31046127 


\title{
Shift work and its relation with meal and snack patterns among healthcare workers
}

\author{
by Gerben Hulsegge, PhD, ${ }^{1}$ Bette Loef, MSc, 1,2 Tessa Benda, MSc, ${ }^{1}$ Allard J van der Beek, PhD, ${ }^{1}$ Karin I Proper, PhD ${ }^{2}$
}

\begin{abstract}
Hulsegge G, Loef B, Benda T, van der Beek AJ, Proper Kl. Shift work and its relation with meal and snack patterns among healthcare workers. Scand J Work Environ Health. 2020;46(2):143-151. doi:10.5271/sjweh.3829
\end{abstract}

\begin{abstract}
Objective Unfavorable eating patterns might contribute to the adverse health effects of shift work. Our objective was to examine differences in meal and snack frequency, as well as the quality of snacks, between shift and day workers and between different types of shifts.

Methods Cross-sectional data from 485 healthcare workers aged 18-65 years of the Klokwerk+ cohort study was used. Dietary intake was assessed using 3-day food diaries, and meals and snacks were classified by the food-based classification of eating episodes method. Using multivariable-adjusted regression analyses, we estimated differences in meal and snack frequency and the quality of snacks between shift and day workers. Within the shift working group, eating frequency on day, evening, and night shifts were compared to work-free days.

Results Meal and snack frequency as well as the quality of snacks showed no significant differences between shift and day workers $(\mathrm{P} \geq 0.05)$. Shift workers had a higher frequency of high-quality snacks $[\beta 0.29,95 \%$ confidence interval (CI) $0.12-0.46]$ and a lower frequency of low-quality snacks ( $\beta-0.29,95 \%$ CI $-0.49--0.09$ ) on evening shifts compared to their work-free days. Compared to work-free days, shift workers had a higher frequency of high-quality snacks on days shifts ( $\beta 0.24,95 \%$ CI $0.10-0.38)$, and only those aged $\leq 40$ years had a higher frequency of snacks on night shifts $(\beta 0.53,95 \%$ CI $0.06-1.00)$ (interaction by age $\mathrm{P}<0.05)$.
\end{abstract}

Conclusion This study observed no differences between day and shift workers either in meal and snack frequency or in the quality of snacks. However, snacking patterns differed across shifts. Future research should investigate whether these snacking patterns contribute to the adverse health effects of shift work.

Key terms diet; dietary intake; meal pattern; night work; nutrition; shift worker; snacking behavior.

Our 24/7 society is going hand-in-hand with the growing necessity of working around the clock. This has resulted in a rapid increase in the number of shift workers in the last decades. Nowadays, approximately $20 \%$ of all workers in industrialized nations are shift workers or work during the night $(1,2)$. However, the chronic disruption of circadian rhythms due to shift work has been associated with detrimental effects on health, such as an increased risk of overweight, gastrointestinal disorders, and cardiovascular diseases (3-6).

Food intake has been suggested as a possible cause of the adverse health effects of shift work (7-10). Most earlier studies focused on the relation between shift work and specific nutrients, such as fat intake and total energy intake $(10,11)$. However, this approach resulted in conflicting findings $(10,11)$. An important reason for this may be that people consume combinations of foods as meals and snacks rather than as specific nutrients. In general, people eat three large meals per day that consist of a combination of animal proteins, starch, and/or vegetable/fruit. This regular frequency of meals has been associated with lower risk of overweight and cardiometabolic risk factors compared to less regular meal patterns (eg, skipping breakfast) (12). Between the three large meals, people often consume snacks in the form of fruits, cookies, sugar-sweetened beverages, or other refreshments. The quality of these snacks differs substantially, and has an impact on health. High-quality

1 Amsterdam UMC, Vrije Universiteit Amsterdam, Department of Public and Occupational Health, Amsterdam Public Health Research Institute, Amsterdam, The Netherlands.

2 Centre for Nutrition, Prevention and Health Services, National Institute for Public Health and the Environment, The Netherlands.

Correspondence to: Karin Proper, Centre for Nutrition, Prevention and Health Services, National Institute for Public Health and the Environment, P.O. Box 1, 3720 BA, Bilthoven, The Netherlands. [E-mail: karin.proper@rivm.nl]. 
snacks, such as fruits or vegetables, are beneficial for health (13), whereas low-quality snacks, typically high in sugar, fat and salt, are detrimental for health (14-16). Understanding the relation between shift work and meal and snack patterns, here defined by frequency of meals and snacks, and quality of snacks, might help to elucidate the contribution of diet to the adverse health effects of shift work.

The few previous studies that examined the link between shift work and eating frequency reported mixed findings (10). Shift workers seem to consume more sugar-sweetened beverages and snacks than day workers (17-19). One study also showed that shift workers tend to consume smaller meals more frequently and at more irregular times, but with an equal total energy intake (20). A study of Geliebter et al (21) showed late-shift workers (evening and night shifts) consumed less meals than day workers. Sudo \& Ohtsuka (22) also reported a lower meal frequency and poorer meal quality among shift workers. Finally, another study observed no differences in meal and snack frequency between morning, evening, and night workers (23). Most of these studies (i) had a rather small study population $(\mathrm{N}=7-137)(19$, $20,22,23$ ), (ii) used retrospective questionnaires prone to recall bias $(18,20,21,24)$, (iii) did not take relevant confounders into account $(8,17,20,23)$, (iv) focused on single nutrients or foods $(8,17,20)$, and/or (v) did not use a valid and reliable method to categorize meals and snacks (17-22). Another gap in the current literature is that most studies only took overall differences between shift and day workers into account. Yet, studying differences across different types of shifts (eg, evening and night shift) among shift workers helps to understand the sources of potential nutritional problems in shift workers. We hypothesize shift workers to have, in particular during night shifts, a higher meal and snack frequency and a lower snack quality than day workers because of increased hunger due to sleep restrictions and the fact they are longer awake during night shifts (25-27).

The first aim of this study was to evaluate differences between shift and day workers in meal and snack frequency and quality of snacks. The second aim was to investigate differences in these dietary outcomes within shift workers, across day, evening, and night shifts compared to their work-free days. As previous studies showed the association between shift work and dietary intake to differ between older and younger workers and between men and women (28-31), we also aimed to investigate whether age and gender are effect modifiers in the association between shift work and eating frequency

\section{Methods}

\section{Study design}

Klokwerk + is a cohort study of healthcare workers aged 18-65 years, who were recruited from six hospitals in The Netherlands in the fall of 2016. Details of the study protocol have been described elsewhere (32). Of the 18000 invited healthcare workers, 611 participated in the baseline measurement. For the current study, crosssectional data from food diaries and a questionnaire were used. Exclusion criteria included participants with incomplete (ie, no information on drinks, unreadable data or missing data from $\geq 1$ days) or missing food diaries, missing information on covariates, and those who stopped working in shifts within 6 months before baseline. All healthcare workers provided written informed consent, and the institutional review board of the University Medical Center Utrecht in The Netherlands approved the study.

\section{Meal and snack frequency}

Participants were asked to keep a food diary for three consecutive days, including $\geq 1$ work day and 1 workfree day. A day was defined from the end of a main sleep period to the end of the next main sleep period. In these diaries, participants reported the amount and type of consumed foods and drinks, together with the time of eating and their working times of that day. The eating episodes were categorized using the validated food-based classification of eating episodes (FBCE) to compare dietary patterns between shift and day workers (33). Eating episodes were defined as any occasion when food or calorie-containing drinks were consumed. All eating episodes within 30 minutes were considered one eating episode (34).

Based on the combination of foods (animal protein, starch, vegetables/fruits, fats, sugars) eaten at one point in time, eating episodes were classified as either a meal or a snack. Categorization of meals and snacks is not based on portion size but on the combination of types of food eaten at one point in time. Meals had to consist of a combination of animal proteins (eg, meats, dairy or eggs) together with a starch (eg, bread, beans or rice) and a vegetable or fruit to be labelled a complete meal. If one of these three components were missing, then the meal was classified as either an incomplete (without a vegetable or fruit), less-balanced (without a starch) or vegetarian meal (without an animal protein). Snacks were categorized as high-quality, mixed-quality, or lowquality snacks. Snacks were considered a high-quality snack if they contained only one product from the animal protein, starch or fruit/vegetable category, such as yoghurt, bread or an apple. Snacks were considered 
of mixed-quality if they consisted of a combination of a high-quality product (eg, yoghurt, bread or an apple) with a low-quality product, ie, high in fat or sugar (eg, fatty sauces or cookies). If the snack only consisted of a low-quality product, then it was labelled a low-quality snack. More detailed information about the meal and snack categories are described in supplemental tables S1-2 (www.sjweh.fi/show_abstract.php?abstract $\mathrm{id}=3829)$ and elsewhere (33).

\section{Shift work}

In the baseline questionnaire, questions based on the domains of Stevens et al (35) international consensus report by were used to determine shift work exposure. Information about participants' working schedule, shift types, and shift work history was obtained, including the number of shifts per month, and the start and stop times of the different shift types. Information about the total years worked in night shifts (shifts between 24:00-06.00 hours) and rotating shifts (rotating between day, night, evening and/or sleep shifts) was collected. Participants were allocated to two groups: day workers who only worked during the day (mostly between 08:00-16:30 hours or 08:30-17:00 hours) and rotating shift workers who rotated between day (mostly between 07:30-16:00 hours), evening (mostly between 15:00-23:00 hours) and night shifts (mostly between 23:00-07:30 hours). Work-free days were defined as any day in which the participant did not have to work. Within the shift worker group, the food diaries were used to distinguish between work-free days and different shift types (ie, day, evening, and night shift) during the 3-day period of completion of the food diary.

\section{Covariates}

Covariates were measured using standardized questionnaires. We measured the socio-demographic factors age (years), gender (male or female), marital status (married/ living together or married/living together), educational level (low: intermediate vocational education/higher secondary education or high: higher vocational education/university), occupation (nurse or other health care worker), and working hours/week (continuous). We also measured the lifestyle factors smoking (current smoker or non-smoker) and physical activity level (minutes of moderate to vigorous activity per week) using the Short Questionnaire to Assess Health-Enhancing Physical Activity (36).

\section{Statistical analysis}

Linear regression analyses were performed to determine the differences in the number of meals and snacks and quality of snacks between shift and day workers. Possible dose-response relations for duration and frequency of night shift work were also studied. Shift workers were categorized by duration of night shift work (no night shifts, $<10,10-19$ and $\geq 20$ years) and by frequency of night shifts $(0,1-4$, and $\geq 5$ night shifts per month), and compared to day workers as a reference category. These analyzes were adjusted for age, gender, marital status, educational level, occupation, smoking, physical activity level, and working hours.

To gain more insight into the potential differences in meal and snack frequency and quality of snacks between shift types, we separately described eating frequencies in shift workers for each type of shift (ie, work-free day, and day, evening, and night shift). Within-person comparisons across these types of shifts were analyzed using linear mixed models. Work-free days were used as a reference category because most shift workers had at least one work-free day within the three food diary days due to choices in the design of our study. In sensitivity analyses, we adjusted the within-person comparisons for weekday (weekday versus weekend day) because diet habits have been found to differ across days of the week (37-39).

For all analyzes, we tested for differences by gender and age as continuous variables using interaction terms. In case of a significant interaction $(\mathrm{P}<0.05)$, stratified analyses by gender (male and female) and age were performed. For the stratified analyses, age was dichotomized by the median age of the shift workers (40 years). All analyses were carried out using IBM SPSS Statistics version 24.0 (IBM Corp, Armonk, NY, USA) and two-sided P-values $<0.05$ were considered statistically significant.

\section{Results}

\section{Participants}

Of the 594 participating healthcare workers with available food diaries, we excluded 98 due to incomplete food diaries, 7 who recently stopped working in shifts, and 4 with missing values on covariates (figure 1). This led to a study population of 78 day workers and 407 shift workers. Of the 407 shift workers, 328 completed their diary on $\geq 1$ work-free day, 212 on $\geq 1$ day shift, 104 on $\geq 1$ evening shift, and 83 on $\geq 1$ night shifts.

Shift workers were on average 40.8 [standard deviation (SD) 11.9] years of age and day workers 47.3 (SD 10.8) years (table 1). Most shift (89.7\%) and day $(83.3 \%)$ workers were women. Shift workers were more often low educated than day workers $(44.5 \%$ versus $28.2 \%$ ). Compared to day workers, shift workers were 


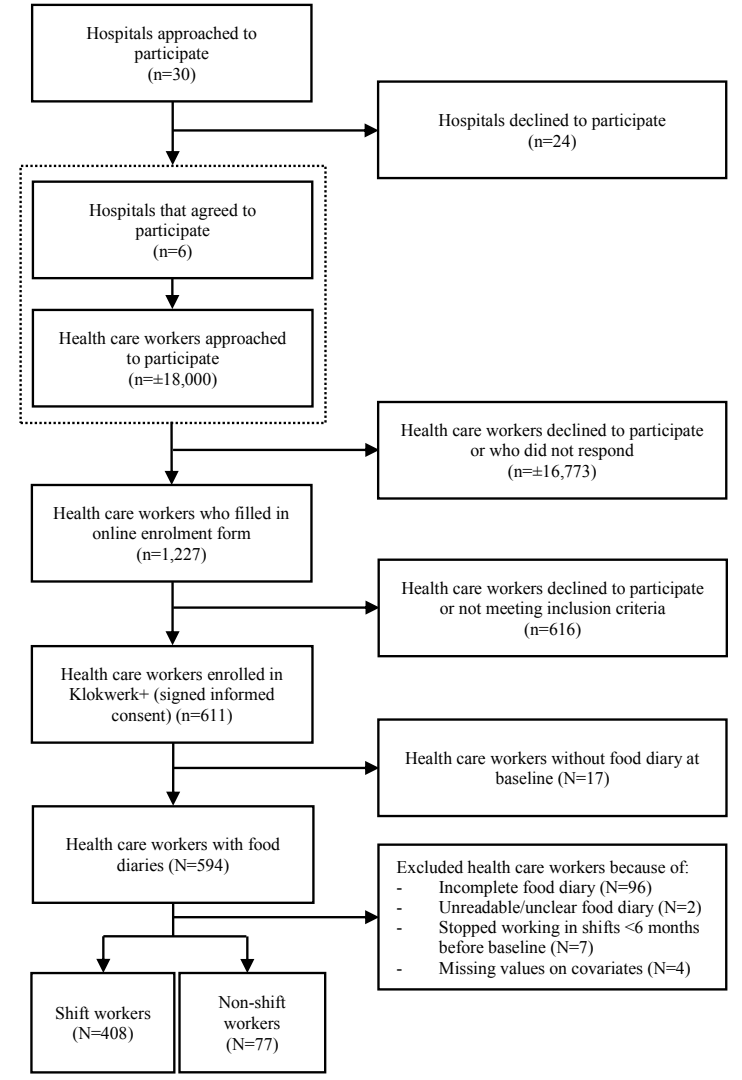

Figure 1. Flow chart leading to the study population.

more often smokers (12.3\% versus 3.8\%) and reported to have a higher weekly physical activity level (1401 minutes versus 1072 minutes).

\section{Differences between shift and day workers}

The median frequency of total eating episodes (ie, meals and snacks combined) was 6.0 [interquartile range (IQR) 5.0-6.7] in shift workers and 5.7 (IQR 4.9-6.7) in day workers. Shift workers had a median total frequency of meals of 2.7 (IQR 2.0-3.0) and day workers of 2.3 (IQR 2.0-3.0). The median frequency of total snack consumption was 3.3 (IQR 2.3-4.3) in shift workers and 3.0 (IQR 2.2-4.0) in day workers (table 1).

The multivariable-adjusted models showed no statistically significant differences in meal or snack frequency between shift and day workers ( $\mathrm{P} \geq 0.05$ ) (table 2 ). This was the case for all different types of meals and for the number of low, mixed, and high-quality snacks. Only for the frequency of total eating episodes was there effect modification by gender $(\mathrm{P}<0.05)$. We found a statistically significant difference in frequency of total eating episodes in women $[\beta 0.39,95 \%$ confidence interval (CI) $0.02-0.75$ ] but not in men ( $\beta-0.35,95 \%$ CI -1.36 $0.67)$. There was no effect modification by age in any of these analyses. For both duration and frequency of night shift work, no dose-response relation was observed for the frequency of meals and snacks (data not shown).

\section{Differences among shift workers by types of shifts}

Median frequency of meal and snack frequency by type of shift is presented in supplementary table S3 (www.sjweh.fi/show_abstract.php?abstract_id $=3829$ ). Shift workers had a higher total meal $(\beta 0 . \overline{27}, 95 \%$ CI $0.15-0.38)$ and high-quality snack frequency $(\beta 0.24$, 95\% CI 0.10-0.38) on day shifts compared to their work-free days (table 3). Especially in those aged $\leq 40$ years, a higher total eating and high-quality snack frequency was observed on day shifts compared to workfree days (interaction for age $\mathrm{P}<0.05$ ) (supplementary table S4, www.sjweh.fi/show_abstract.php?abstract $\mathrm{id}=3829$ ). Also, during night shifts, their frequency of total snacks ( $\beta 0.53,95 \%$ CI $0.06-1.00)$, mostly mixed-quality snacks ( $\beta 0.28,95 \%$ CI $0.01-0.54)$ was higher than on their work-free days (interaction for age $\mathrm{P}<0.05$ ) (supplemental table $\mathrm{S} 4$ ). Among all shift workers, irrespective of age, total snack frequency ( $\beta$ $0.05,95 \% \mathrm{CI}--0.22-0.33$ ) did not differ during evening shifts compared to work-free days. However, they had a healthier snack pattern, with a higher frequency of high-quality snacks ( $\beta 0.29,95 \%$ CI $0.12-0.46)$ and a lower frequency of low-quality snacks $(\beta-0.29,95 \% \mathrm{CI}$ $-0.49-0.09$ ) during evening shifts.

Sensitivity analysis showed virtually the same results for the presented within-subject analyses compared to the analyses additionally adjusted for weekday (data not shown).

\section{Discussion}

In the present study among healthcare workers, the meal and snack frequencies and the quality of snacks of shift workers did not differ from those of day workers. Thus, these results do not confirm our hypothesis that shift workers have, in general, a higher meal and snack frequency and eat snacks of poorer quality than day workers. However, among the younger, but not the older shift workers, the eating frequency of total and mixed-quality snacks was higher during night shifts than during their work-free days. During evening shifts, total snack frequency of shift workers did not differ compared to work-free days, but the snacking pattern was of higher quality.

The potential link between shift work and dietary intake has been studied widely but mostly with mixed conclusions (17-24). In line with the present findings, one study among Brazil garbage collectors, which used 
Table 1. Baseline characteristics of day workers $(\mathrm{N}=78)$ and shift workers $(\mathrm{N}=407)$. [NA=not applicable; IQR=interquartile range; $\mathrm{SD}=\mathrm{standard}$ deviation].

\begin{tabular}{|c|c|c|c|c|c|c|}
\hline & \multicolumn{3}{|c|}{ Day workers } & \multicolumn{3}{|c|}{ Shift workers } \\
\hline & Mean (SD) & Median (IQR) & $\mathrm{N}(\%)$ & Mean (SD) & Median (IQR) & $\mathrm{N}(\%)$ \\
\hline \multicolumn{7}{|l|}{ Demographics } \\
\hline Age (years) & $47.3(10.8)$ & & & $40.8(11.9)$ & & \\
\hline Female & & & $65(83.3)$ & & & $365(89.7)$ \\
\hline Low educational level & & & $22(28.2)$ & & & $181(44.5)$ \\
\hline Married, living together & & & $61(78.2)$ & & & $301(74.0)$ \\
\hline \multicolumn{7}{|l|}{ Occupational } \\
\hline \multicolumn{7}{|l|}{ Number of night shifts/month } \\
\hline 0 & & & $78(100)$ & & & $30(7.4)$ \\
\hline $1-4$ & NA & & & & & $240(58.8)$ \\
\hline$\geq 5$ & NA & & & & & $137(33.6)$ \\
\hline \multicolumn{7}{|l|}{ Duration of night shift work } \\
\hline No night-shifts & NA & & & & & $30(7.4)$ \\
\hline Short $(<10$ years) & NA & & & & & 136 (33.4) \\
\hline Intermediate ( $10-19$ years) & NA & & & & & 95 (23.3) \\
\hline Long ( $\geq 20$ years) & NA & & & & & 146 (35.9) \\
\hline \multicolumn{7}{|l|}{ Type of job } \\
\hline Nurse & & & $25(32.1)$ & & & 339 (83.3) \\
\hline Others & & & $53(67.9)$ & & & $68(16.7)$ \\
\hline Working hours/week & $29.3(9.2)$ & & & $31.5(7.0)$ & & \\
\hline \multicolumn{7}{|l|}{ Lifestyle } \\
\hline Current smoker & & & $3(3.8)$ & & & $50(12.3)$ \\
\hline Moderate-to-vigorous physical activity (min/week) & 1072 (951) & & & 1401 (802) & & \\
\hline Body mass index $\left(\mathrm{kg} / \mathrm{m}^{2}\right)$ & $25.2(4.2)$ & & & $25.0(4.0)$ & & \\
\hline \multicolumn{7}{|l|}{ Food-based classification of eating episodes } \\
\hline Total eating episodes & & $5.7(4.9-6.7)$ & & & $6.0(5.0-6.7)$ & \\
\hline \multicolumn{7}{|l|}{ Meals per day } \\
\hline Total & & $2.3(2.0-3.0)$ & & & $2.7(2.0-3.0)$ & \\
\hline Complete & & $1.0(0.7-1.7)$ & & & $1.0(0.7-1.3)$ & \\
\hline Incomplete & & $1.0(0.7-1.3)$ & & & $1.0(0.7-1.3)$ & \\
\hline Less-balanced & & $0.0(0.0-0.3)$ & & & $0.0(0.0-0.3)$ & \\
\hline Vegetarian & & $0.0(0.0-0.3)$ & & & $0.0(0.0-0.3)$ & \\
\hline \multicolumn{7}{|l|}{ Snacks per day } \\
\hline Total & & $3.0(2.2-4.1)$ & & & $3.3(2.3-4.3)$ & \\
\hline High-quality & & $1.0(0.3-1.7)$ & & & $1.0(0.3-1.7)$ & \\
\hline Mixed-quality & & $0.7(0.3-1.0)$ & & & $0.7(0.3-1.3)$ & \\
\hline Low-quality & & $1.3(0.7-1.7)$ & & & $1.3(0.7-2.0)$ & \\
\hline
\end{tabular}

the same food-based classification tool as the present study (ie, FCBE), found no differences in the frequency of meals and snacks between day workers, evening workers and night workers (23). Additionally to that previous study, we found no differences between men and women and no dose-response relation for both duration and frequency of night shifts with meal and snack frequency. In contrast, some studies observed shift workers to have a lower meal frequency than day workers $(21,22,24)$, and higher snack frequency (19). From the latter study, it was unclear whether shift workers ate more low or high-quality snacks, but two studies $(17,19)$, which did not adjust for confounders, showed shift workers to consume more sugar-sweetened beverages than day workers. These differences in outcomes with the present study results might be explained by the lack of validated measurement tools, the differences in study populations, and the fact that most studies did not take relevant confounders, such as age and gender, into account $(17,19,20,23,24)$. Moreover, the effect of shift work on lifestyles and dietary patterns may differ across occupational sectors, availability of food at the workplace (eg, vending machines), and shift schedules (eg, rotating versus fixed shifts). For example, the healthcare workers in the present study might be more conscious about their food intake than the factory workers in two studies with contrasting results $(22,24)$. Thus, in contrast to our hypothesis, there seems to be no large differences in frequency of meals and snacks or quality of snacks between day and shift workers in healthcare, but there might be some differences in certain occupational sectors, shift types, or subgroups.

We observed that younger shift workers (aged $\leq 40$ years) consumed more snacks, mainly those of mixedquality, during night shifts than during work-free days. A possible explanation is that shift workers sleep less during night shifts than on work-free days (26), and sleep restriction has been associated with increased hunger (27). Another possible explanation is that night workers are awake longer due to their later shifts (25), and therefore have more opportunity to eat. In addition, differences in work demands and opportunities for snacking and meal times may differ across shifts and between types of jobs, which may have influenced eat- 
Table 2. Regression coefficients ( $\beta$ ) of differences in number of meals and snacks between shift workers $(\mathrm{N}=407)$ and day workers $(\mathrm{N}=78)$ (reference) according to food-based classification of eating episodes. [Cl=confidence interval.]

\begin{tabular}{|c|c|c|}
\hline \multirow{2}{*}{$\begin{array}{l}\text { Dietary } \\
\text { variables }\end{array}$} & $\beta(95 \% \mathrm{Cl})$ & $\beta(95 \% \mathrm{Cl})$ \\
\hline & Crude & Adjusted $^{\mathrm{a}}$ \\
\hline Total eating episodes & $0.18(-0.14-0.50)^{b}$ & $0.19(-0.15-0.53)^{b}$ \\
\hline \multicolumn{3}{|l|}{ Meals } \\
\hline Tota & $-0.01(-0.15-0.15)$ & $0.02(-0.13-0.18)$ \\
\hline Complete & $-0.05(-0.16-0.07)$ & $-0.06(-0.18-0.07)$ \\
\hline Incomplete & $0.06(-0.09-0.21)$ & $0.09(-0.06-0.25)$ \\
\hline Less-balanced & $-0.02(-0.10-0.05)$ & $-0.02(-0.10-0.06)$ \\
\hline Vegetarian & $0.01(-0.06-0.07)$ & $0.004(-0.06-0.07)$ \\
\hline \multicolumn{3}{|l|}{ Snacks } \\
\hline Total & $0.18(-0.14-0.50)$ & $0.17(-0.17-0.51)$ \\
\hline High-quality & $0.04(-0.17-0.24)$ & $-0.07(-0.14-0.28)$ \\
\hline Mixed-quality & $0.13(-0.04-0.30)$ & $0.15(-0.23-0.33)$ \\
\hline Low-quality & $0.02(-0.22-0.25)$ & $-0.06(-0.30-0.18)$ \\
\hline
\end{tabular}

ing frequency. Compared to day workers, shift workers were more often nurses, who may have different work demands and opportunities for work breaks than other healthcare workers. Although we adjusted for occupation, we were unable to adjust for other potential confounders, including work demands and work breaks. A possible reason for a higher snack frequency on night shifts among younger, but not older, shift workers might be that younger shift workers have, in general, a higher energy expenditure and higher energy needs than older shift workers $(26,40)$. Another explanation might be that the older shift workers are more adapted to their rotating shifts and therefore have healthier snacking habits during night shifts than younger shift workers. During day shifts, we found a higher frequency of highquality snacks among younger shift workers. Although the snacks were of different quality during day and night shifts, this indicates that the younger shift workers might be snacking more during work days than on work-free days. We also found shift workers consumed more high- and less low-quality snacks during evening shifts compared to their work-free days. The reasons for these healthier snacking patterns on evening shifts are unclear, but it might be that there is more temptation to eat and drink low-quality snacks at home than at work during evening shifts. In addition, shift workers may better plan their food intake particularly during evening shifts than on work-free days, for example by bringing fruit to work. This type of planned behavior is a strong predictor of actual behavior (41). Overall, snacking behavior differed across different shifts, with a higher snacking frequency during night shifts among younger shift workers and a healthier snacking pattern during evening shifts among all shift workers.
Table 3. Regression coefficients $(\beta)$ of differences in number of meals and snacks between day shifts ( $N=334)$, evening shifts $(\mathrm{N}=177)$ and night shifts ( $N=154)$ compared to work-free days ( $N=556)$ (reference) among shift workers, according to food-based classification of eating episodes. $[\mathrm{Cl}=$ confidence interval.] Significant associations $(\mathbf{P}<0.05)$ are printed in bold.

\begin{tabular}{|c|c|c|c|}
\hline \multirow{2}{*}{$\begin{array}{l}\text { Dietary } \\
\text { variables }\end{array}$} & \multirow{2}{*}{ 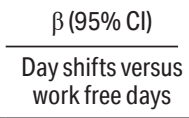 } & \multirow{2}{*}{$\frac{\beta(95 \% \mathrm{Cl})}{\begin{array}{c}\text { Evening shifts versus } \\
\text { work free days }\end{array}}$} & \multirow{2}{*}{ 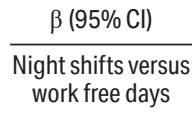 } \\
\hline & & & \\
\hline $\begin{array}{l}\text { Total eating } \\
\text { episodes }\end{array}$ & $0.49(0.26-0.72)$ & $0.07(-0.21-0.36)$ & $0.17(-0.16-0.50)$ \\
\hline \multicolumn{4}{|l|}{ Meals } \\
\hline & $0.27(0$ & $-0.01(-0.16-0.14)$ & $0.14(-0.03-0.31)$ \\
\hline Complete & 7) & 0.01 & 0.05 \\
\hline & & & \\
\hline inced & 0.0 & -0.0 & 0.04 \\
\hline Vegetarian & $-0.03(-0.09-0.02)$ & $-0.03(-0.10-0.03)$ & $0.00(-0.07-0.08)$ \\
\hline \multicolumn{4}{|l|}{ Snacks } \\
\hline Total & 0.22 & 0.05 & 0.03 \\
\hline$\Pi$ & & 0.2 & $2-0.28)$ \\
\hline Mixed-quality & $0.02(-0.10-0.15)$ & $0.06(-0.10-0.22)$ & $-0.01(-0.19-0.17)$ \\
\hline Low-quality & $-0.03(-0.20-0.13)$ & $-0.29(-0.49--0.09)$ & $-0.03(-0.27-0.20)$ \\
\hline
\end{tabular}

We observed no difference in meal and snack frequency or in quality of snacks between day and shift workers, indicating that meal and snack patterns probably do not explain the adverse health effects of shift work. In a subsample of our study population $(\mathrm{N}=300)$, we also did not observe differences in total energy and macronutrient intake between shift and day workers (data not shown). However, eating the same number of meals and snacks during the night and day - even without a change in total energy intake - might still be associated with poorer health outcomes. Research has shown shift workers to have a greater incidence of gastrointestinal disorders, overweight, and cardiovascular disease (42), possibly due to changes in digestion, absorption and storage of foods caused by their rotating shifts (43). The food absorption processes can show an altered function due to various causes: (i) meals consumed in the evening result in a more decreased gastric $\mathrm{PH}$ than those in the morning (7), (ii) a decreased food satiety in the evening (40), (iii) a greater insulin resistance at night, and (iv) a decreased gastrointestinal response at night (44). It is known that eating large meals during night shifts can lead to heartburn or constipation, and food absorption processes, such as glucose tolerance and gastric emptying, are found to be disturbed at night (45). Therefore, it is important to modulate meal patterns of shift workers during the night to best match their daily rhythms of nutrient metabolism and glucose tolerance, which may mitigate adverse health effects (46). Replacing large meals by smaller meals or snacks, especially high-quality snacks, during night shifts might be advantageous (45). However, before detailed recommendations on meal patterns can be made, future research should determine the optimal meal patterns, 
including timing of meals, during irregular shifts for overall health.

A strength of the present study is that we used a larger sample size than previous studies investigating shift work and diet $(19,22,23,47)$. Moreover, we used validated measurement tools to measure meal and snack frequency based on well-filled food diaries. In contrast to other studies $(18,20,22)$, we were able to investigate differences within shift workers across different shifts and assess differences between age groups. However, there were also some limitations, including the relatively low response rate of the study. Individuals who participate in studies are generally healthier and better educated than non-responders. Although we expect differences in characteristics of responders and non-responders not to differ between shift workers and day workers, generalization of the results might be limited. In addition, no conclusions can be drawn about differences in quantity of diet between shift and day workers. As total energy and macronutrient intake did not differ between shift and day workers in a subsample of the study population, it is unlikely that energy and macronutrient intake influenced the results of the present study. Three-day diaries have been shown to accurately measure eating frequency (48), but due to the limited number of measurement days we were unable to directly compare day, evening, and night shifts. Duration of rest time between work shifts and meal breaks may differ across shifts and influence meal and snack frequency. As we did not have information on duration of rest time and break patterns, we were unable to take these factors into account as explanation for possible differences in meal and snack frequency between shift and day workers, and between different types of shifts among shift workers. Furthermore, work-free days could either be before or after a workday. This may have influenced the food availability at home and possibilities to bring food to work. As this is the case for both shift workers and day workers, this is unlikely to have a large impact on the results. Finally, a large part of the day workers in our study had previously worked in irregular shifts. As they left shift work on average $>10$ years ago, the effects of shift work on their present diet pattern, is probably limited.

In the present study, no differences were observed - either in meal and snack frequency or in snack quality - between shift and day workers, indicating that meal and snack patterns probably do not explain the increased risk of overweight and cardiovascular disease among shift workers. However, meal patterns of shift workers should be matched to their circadian rhythms (46), and eating less large meals and smaller meals or high-quality snacks during night shifts might, therefore, be favorable. Future research should investigate which meal and snack patterns across different shifts are most beneficial for health to improve dietary recommendations for shift workers.

\section{Acknowledgements}

This study was funded by the Strategic Program project 24/7 Health of the Dutch National Institute for Public Health and the Environment (Grant number: 24/7 health) and the Netherlands Organisation for Health Research and Development (grant number: 531001409). The funding bodies had no role in the study design; collection, analysis, and interpretation of data; writing of the manuscript; or the decision to submit the manuscript for publication.

\section{Conflict of interest}

No potential conflicts of interest relevant to this article were reported.

\section{References}

1. European Foundation for the Improvement of Living and Working Conditions (Eurofound). Sixth European Working Conditions Survey - Overview report. Publications Office of the European Union: Luxembourg, 2016.

2. Beers T. Flexible schedules and shift work: replacing the '9-to-5' workday? Mon Labor Rev 2000;23:33-40.

3. Di Lorenzo L, De Pergola G, Zocchetti C, L'Abbate N, Basso A, Pannacciulli N et al. Effect of shift work on body mass index: results of a study performed in 319 glucosetolerant men working in a Southern Italian industry. Int $\mathrm{J}$ Obes Relat Metab Disord 2003 Nov;27(11):1353-8. https:// doi.org/10.1038/sj.ijo.0802419.

4. Karlsson B, Knutsson A, Lindahl B. Is there an association between shift work and having a metabolic syndrome? Results from a population based study of 27,485 people. Occup Environ Med 2001 Nov;58(11):747-52. https://doi. org/10.1136/oem.58.11.747.

5. Knutsson A, Bøggild H. Gastrointestinal disorders among shift workers. Scand J Work Environ Health 2010 Mar;36(2):85-95. https://doi.org/10.5271/sjweh.2897.

6. Puttonen S, Härmä M, Hublin C. Shift work and cardiovascular disease - pathways from circadian stress to morbidity. Scand J Work Environ Health 2010 Mar;36(2):96-108. https://doi.org/10.5271/sjweh.2894.

7. Fritschi L, Glass DC, Heyworth JS, Aronson K, Girschik J, Boyle T et al. Hypotheses for mechanisms linking shiftwork and cancer. Med Hypotheses 2011 Sep;77(3):430-6. https:// doi.org/10.1016/j.mehy.2011.06.002.

8. Wang F, Yeung KL, Chan WC, Kwok CC, Leung SL, Wu C 
et al. A meta-analysis on dose-response relationship between night shift work and the risk of breast cancer. Ann Oncol 2013 Nov;24(11):2724-32. https://doi.org/10.1093/annonc/ mdt283.

9. Zhao I, Turner C. The Impact of Shift Work on People's Daily Health Habits and Adverse Health Outcomes. Aust J Adv Nurs 2008;25:8-22.

10. Souza RV, Sarmento RA, de Almeida JC, Canuto R. The effect of shift work on eating habits: a systematic review. Scand J Work Environ Health 2019 Jan;45(1):7-21. https:// doi.org/10.5271/sjweh.3759.

11. Lowden A, Moreno C, Holmbäck U, Lennernäs M, Tucker P. Eating and shift work - effects on habits, metabolism and performance. Scand J Work Environ Health 2010 Mar;36(2):150-62. https://doi.org/10.5271/sjweh.2898.

12. Pot GK, Almoosawi S, Stephen AM. Meal irregularity and cardiometabolic consequences: results from observational and intervention studies. Proc Nutr Soc 2016 Nov;75(4):47586. https://doi.org/10.1017/S0029665116000239.

13. Boeing H, Bechthold A, Bub A, Ellinger S, Haller D, Kroke A et al. Critical review: vegetables and fruit in the prevention of chronic diseases. Eur J Nutr 2012 Sep;51(6):637-63. https://doi.org/10.1007/s00394-012-0380-y.

14. Bellisle F. Meals and snacking, diet quality and energy balance. Physiol Behav 2014 Jul;134:38-43. https://doi. org/10.1016/j.physbeh.2014.03.010.

15. Te Morenga L, Mallard S, Mann J. Dietary sugars and body weight: systematic review and meta-analyses of randomised controlled trials and cohort studies. BMJ 2012 Jan;346:e7492. https://doi.org/10.1136/bmj.e7492.

16. Vartanian LR, Schwartz MB, Brownell KD. Effects of soft drink consumption on nutrition and health: a systematic review and meta-analysis. Am J Public Health 2007 Apr;97(4):667-75. https://doi.org/10.2105/ AJPH.2005.083782.

17. Lasfargues G, Vol S, Cacès E, Le Clésiau H, Lecomte $\mathrm{P}$, Tichet J. Relations among night work, dietary habits, biological measure, and health status. Int $\mathrm{J}$ Behav Med 1996;3(2):123-34. https://doi.org/10.1207/ s15327558ijbm0302_3.

18. Tada Y, Kawano Y, Maeda I, Yoshizaki T, Sunami A, Yokoyama $\mathrm{Y}$ et al. Association of body mass index with lifestyle and rotating shift work in Japanese female nurses. Obesity (Silver Spring) 2014 Dec;22(12):2489-93.

19. Waterhouse J, Buckley P, Edwards B, Reilly T. Measurement of, and some reasons for, differences in eating habits between night and day workers. Chronobiol Int 2003 Nov;20(6):1075-92. https://doi.org/10.1081/CBI120025536 .

20. Heath G, Roach GD, Dorrian J, Ferguson SA, Darwent D, Sargent C. The effect of sleep restriction on snacking behaviour during a week of simulated shiftwork. Accid Anal Prev 2012 Mar;45 Suppl:62-7. . https://doi.org/10.1016/j. aap.2011.09.028

21. Geliebter A, Gluck ME, Tanowitz M, Aronoff NJ, Zammit
GK. Work-shift period and weight change. Nutrition 2000 Jan;16(1):27-9. https://doi.org/10.1016/S08999007(99)00228-2.

22. Sudo N, Ohtsuka R. Nutrient intake among female shift workers in a computer factory in Japan. Int $\mathrm{J}$ Food Sci Nutr 2001 Jul;52(4):367-78. https://doi. org/10.1080/09637480120057530.

23. de Assis MA, Nahas MV, Bellisle F, Kupek E. Meals, snacks and food choices in Brazilian shift workers with high energy expenditure. J Hum Nutr Diet 2003 Aug;16(4):283-9. https://doi.org/10.1046/j.1365-277X.2003.00448.x.

24. Takagi K. Influence of shift work on time and frequency of meal taking. J Hum Ergol (Tokyo) 1972 Dec;1(2):195-205.

25. Juda M, Vetter C, Roenneberg T. Chronotype modulates sleep duration, sleep quality, and social jet lag in shiftworkers. J Biol Rhythms 2013 Apr;28(2):141-51. https:// doi.org/10.1177/0748730412475042.

26. Roberts SB, Fuss P, Heyman MB, Young VR. Influence of age on energy requirements. Am J Clin Nutr 1995 Nov;62(5 Suppl):1053S-8S. https://doi.org/10.1093/ajen/62.5.1053S.

27. Spiegel K, Tasali E, Penev P, Van Cauter E. Brief communication: sleep curtailment in healthy young men is associated with decreased leptin levels, elevated ghrelin levels, and increased hunger and appetite. Ann Intern Med 2004 Dec;141(11):846-50. https://doi.org/10.7326/00034819-141-11-200412070-00008.

28. Hemiö K, Puttonen S, Viitasalo K, Härmä M, Peltonen $\mathrm{M}$, Lindström J. Food and nutrient intake among workers with different shift systems. Occup Environ Med 2015 Jul;72(7):513-20. https://doi.org/10.1136/ oemed-2014-102624.

29. Hulsegge G, Boer JM, van der Beek AJ, Verschuren WM, Sluijs I, Vermeulen R et al. Shift workers have a similar diet quality but higher energy intake than day workers. Scand J Work Environ Health 2016 Jun;42(6):459-68. https://doi. org/10.5271/sjweh.3593.

30. Morikawa Y, Miura K, Sasaki S, Yoshita K, Yoneyama S, Sakurai $\mathrm{M}$ et al. Evaluation of the effects of shift work on nutrient intake: a cross-sectional study. J Occup Health 2008;50(3):270-8. https://doi.org/10.1539/joh.L7116.

31. Seibt R, Süße T, Spitzer S, Hunger B, Rudolf M. Nutrition and health in hotel staff on different shift patterns. Occup Med (Lond) 2015 Aug;65(6):477-84. https://doi. org/10.1093/occmed/kqv068.

32. Loef B, van Baarle D, van der Beek AJ, van Kerkhof LW, van de Langenberg D, Proper KI. Klokwerk+study protocol: an observational study to the effects of night-shift work on body weight and infection susceptibility and the mechanisms underlying these health effects. BMC Public Health 2016 Aug;16:692. https://doi.org/10.1186/s12889016-3317-1.

33. Lennernas M, Andersson I. Food-based classification of eating episodes (FBCE). Appetite. 1999;32:53-65.

34. Ovaskainen ML, Tapanainen H, Pakkala H. Changes in the contribution of snacks to the daily energy intake of 
Finnish adults. Appetite 2010 Jun;54(3):623-6. https://doi. org/10.1016/j.appet.2010.03.012.

35. Stevens RG, Hansen J, Costa G, Haus E, Kauppinen T, Aronson $\mathrm{KJ}$ et al. Considerations of circadian impact for defining 'shift work' in cancer studies: IARC Working Group Report. Occup Environ Med 2011 Feb;68(2):154-62. https://doi.org/10.1136/oem.2009.053512.

36. Wendel-Vos GC, Schuit AJ, Saris WH, Kromhout D. Reproducibility and relative validity of the short questionnaire to assess health-enhancing physical activity. J Clin Epidemiol 2003 Dec;56(12):1163-9. https://doi. org/10.1016/S0895-4356(03)00220-8.

37. An R. Weekend-weekday differences in diet among U.S. adults, 2003-2012. Ann Epidemiol 2016 Jan;26(1):57-65. https://doi.org/10.1016/j.annepidem.2015.10.010.

38. Yang PH, Black JL, Barr SI, Vatanparast H. Examining differences in nutrient intake and dietary quality on weekdays versus weekend days in Canada. Appl Physiol Nutr Metab 2014 Dec;39(12):1413-7. https://doi. org/10.1139/apnm-2014-0110.

39. Bhargava A, Forthofer R, McPherson S, Nichaman M. Estimating the variations and autocorrelations in dietary intakes on weekdays and weekends. Stat Med 1994 Jan;13(2):113-26. https://doi.org/10.1002/sim.4780130203.

40. Howarth NC, Huang TT, Roberts SB, Lin BH, McCrory MA. Eating patterns and dietary composition in relation to BMI in younger and older adults. Int J Obes (Lond). 2007;31:675-84.
41. Ajzen I. The theory of planned behavior. Organ Behav Hum Decis Process 1991;50:179-211. https://doi. org/10.1016/0749-5978(91)90020-T.

42. Costa G. The impact of shift and night work on health. Appl Ergon. 1996;27:9-16.

43. Waterhouse J, Minors D, Atkinson G, Benton D. Chronobiology and meal times: internal and external factors. Br J Nutr 1997;77 Suppl 1:S29-38. https://doi.org/10.1079/ BJN19970102.

44. Holmback U, Lowden A, Akerfeldt T, Lennernas M, Hambraeus L, Forslund J et al. The human body may buffer small differences in meal size and timing during a $24-\mathrm{h}$ wake period provided energy balance is maintained. J Nutr. 2003;133:2748-55.

45. Centofanti S, Dorrian J, Hilditch C, Grant C, Coates A, Banks $\mathrm{S}$. Eating on nightshift: a big vs small snack impairs glucose response to breakfast. Neurobiol Sleep Circadian Rhythms 2018;4:44-52. https://doi.org/10.1016/j.nbscr.2017.12.001.

46. Hutchison AT, Heilbronn LK. Metabolic impacts of altering meal frequency and timing - Does when we eat matter? Biochimie 2016 May;124:187-97. https://doi.org/10.1016/j. biochi.2015.07.025.

47. Fraser GE, Welch A, Luben R, Bingham SA, Day NE. The effect of age, sex, and education on food consumption of a middle-aged English cohort-EPIC in East Anglia. Prev Med 2000 Jan;30(1):26-34. https://doi.org/10.1006/ pmed.1999.0598.

48. Krall EA, Dwyer JT. Validity of a food frequency questionnaire and a food diary in a short-term recall situation. J Am Diet Assoc 1987 Oct;87(10):1374-7.

Received for publication: 15 January 2019 